\title{
Applications of Kelly's Personal Construct Theory to Vocational Guidance
}

\author{
Anna Paszkowska-Rogacz, Zofia Kabzińska \\ University of Lodz, Lodz, Poland
}

\begin{abstract}
This paper outlines selected applications of Kelly's Personal Construct Theory to vocational guidance. The authors elicited personal constructs using the Rep Test (Role Construct Repertory Test) and compared them with Holland's occupational typology. The sample $(N=136, F=85, M=51$, average age of 21.97) was composed of students of various universities in Lodz, Poland. Two diagnostic methods were used: the Vocational Preference Questionnaire Job-6 and a Rep Test focused on job-related constructs. The authors used multi-dimensional scaling to analyze and visualize the results. The results show that the application of Kelly's Personal Construct Theory to vocational guidance is a valuable approach, which affords results complementary to those obtained with questionnaire-based methods.
\end{abstract}

Keywords: personal constructs, career counseling, diagnosis

\section{Introduction}

The Personal Construct Theory was presented by George Kelly in 1955 (Pervin \& John, 2002). Therefore, it can be considered as neither a new nor a revolutionary approach. Over the years, it has been thoroughly revised and developed. It has also been successfully applied to many fields of research and practice. It is a constructivist theory that aims to explain the individual's beliefs and world view by his/her "personal constructs"- cognitive dimensions formed by two opposite poles. The repertory of a person's constructs and relationships between them provides a basis for predicting his/her behaviors and judgments. The main advantage of this theory is the fact that it uncovers tacit knowledge, which is used by individuals in everyday life, but it is very hard to verbalize. In contrast to Freud's theory focusing on sub-conscious processes and to behaviorism aiming to define human behavior in terms of the stimulus-response model, Kelly believed that human activity is driven by the need to control reality. The individual gains a sense of control when he/she understands the events that happen to him/her and is able to predict from experience what is likely to happen in the future. The desire to control the environment and anticipate events is one of the basic and most motivating needs (Côté, 1996). This is why, in Kelly's (1955/1991) theory, the individual is an active "scientist" who constantly analyzes the surrounding reality, observes and looks for patterns, formulates hypotheses about the causes of events, builds theories, and makes conclusions based on gained experience.

Anna Paszkowska-Rogacz, Ph.D., Institute of Psychology, Department of Occupational Psychology and Career Counseling, University of Lodz.

Zofia Kabzińska, M.A., Institute of Psychology, Department of Occupational Psychology and Career Counseling, University of Lodz. 
Kelly (1955/1991) argued that the model of a scientist's activity reflects well, the way in which people generally behave. Cognitive processes, such as thinking, remembering, and problem-solving play a key role in the development of personality.

People give meaning and significance to events, selecting similarities and differences that describe them from the sum of their experiences. Mental structures that are used to interpret and predict events are personal constructs. They can be defined as "bipolar concepts (such as, strong-weak, happy-sad, like me-unlike me, etc.) used to categorize the objects of an individual's cognition (people, situations) and to abstract similarities and differences between them" (Kofta \& Dolinski, 2004, p. 564), or more simply, as "basic units of description and analysis" (Jankowicz, 2004, p. 10).

Every person has a distinct and inimitable system of constructs. Therefore, the perspective from which he/she perceives reality is unique. The personal and private nature of constructs explains why similar situations are usually differently perceived by different people. In Kelly's theory, it is not important whether an event perceived by an individual actually exists or not; what matters are the mere fact that the individual perceives it as real. Spokane (1992) compared an individual system of constructs with a lens through which the person views the world. Every individual creates his/her own subjective system of meanings. On this basis, he/she builds relationships between elements of the external environment and ways to deal with the stimuli coming from outside. This "individual reality" determines one's behavior and relationships with others.

According to Kelly's theory, every behavior is in fact an instance of testing one's current system of constructs. In most everyday situations, this process is very intuitive and unconscious. Individuals make certain assumptions about reality in an automatic way.

Kelly based his theory on the philosophical approach called "constructive alternativism", according to which every individual has a choice of various options of giving meaning to events, or constructing reality (Fransella \& Dalton, 2000; Boeree, 2006). Of course, this does not mean that all constructions are equally effective in anticipating events, but this does refute the existence of any definite and undisputed criteria.

The Personal Construct Theory is based on the so-called "fundamental postulate" stating that, "A person's psychological processes are channelized by the ways in which he/she anticipates events" (Kelly, 1966, p. 7) and on 11 corollaries explaining the basic concepts and specifying the main issues concerning the system of constructs.

Kelly proposed not only a complex and well-developed theory, but also a diagnostic tool adapted to it. The Rep Test (Role Construct Repertory Test) was created as a methodological complement to the Personal Construct Theory. In Kelly's opinion, the easiest way to learn about the personal constructs of a client is to ask him/her about them (Pervin \& John, 2002; Czapiński, 1978). Thus, the test has the form of a structured interview which can be used to elicit personal constructs concerning a specific topic.

No single Rep Test can reveal the respondent's complete system of constructs; rather, it only leads to obtaining a representative sample of constructs and shows the way in which the respondent uses them (Beail, 1985).

According to Jankowicz (2004), the Rep Test can be described as:

(1) A form of a structured interview, with or without ratings, which gives an opportunity to elicit the client's point of view, untainted by the opinion of the researcher;

(2) An ideal way to conduct a pilot study;

(3) A useful research tool, which integrates both a qualitative and a quantitative approach. 
Over the years, a number of different variants of the Rep Test have been developed. However, the basic procedure proposed by Kelly (1955/1991) has not changed significantly. Regardless of the purpose, place, and manner in which it is implemented, a Rep Test is composed of the following components (Jankowicz, 2004):

(1) Topic - specific, clearly defined and fitted to the experience of the individual. It can be related to any aspect of the individual's life, such as family, career, work, etc.;

(2) Elements - examples representative of a given topic (e.g., job titles, names of colleagues, etc.);

(3) Constructs - criteria used by the individual to categorize and distinguish between the elements. They reflect the subjective importance that each phenomenon has for the individual;

(4) Rating - each element is evaluated in terms of similarity to one of the contrasting poles of a particular construct.

The Rep Test technique is very flexible and can be adapted to many contexts. Nevertheless, five successive stages can be generally distinguished (Beail, 1985):

(1) Selection of elements;

(2) Elicitation of constructs - most often (in accordance with Kelly's idea) this is done by comparing consecutive, randomly selected triads of elements. The subject is asked to answer the following question: "Which two of the presented elements are similar, and different from the third one?". On this basis, the two poles of a construct are delimited;

(3) Filling in a matrix;

(4) Analysis;

(5) Interpretation.

Due to the idiographic characteristics of the Rep Test, it can be hardly considered in terms of traditional psychometric values, such as validity and reliability (Slater, 1976, cited in Smith, Hartley, \& Stewart, 1978).

One of the fundamental assumptions of the Rep Test is that the mathematical relationships between different constructs reflect the psychological relationships between them, as they are subjectively perceived by the subject. Therefore, notwithstanding the fact that the Rep Test is a valuable source of qualitative data, the matrix of results obtained on its basis may be subjected to extensive statistical analysis ranging from relatively simple and descriptive statistics, such as average ratings for each element, to relatively advanced procedures, and cluster analysis, principal component analysis, or multidimensional scaling.

Quantitative methods are still frequently used in the practice of vocational guidance. They are based on trait and factor theories, and therefore, present a totally different approach from Kelly's Personal Construct Theory. One of the most popular approaches used in Poland is Holland's Vocational Personality Theory (1997), which assumes the existence of six modal orientations or vocational personality types, such as realistic, investigative, artistic, social, enterprising, and conventional. Every person reveals the characteristics of each of the six personality types, which occur hierarchically in descending intensity.

Inventories, such as the SDS (Self-directed Search) (Holland, Powell, \& Fritzsche, 1994), the VPI (Vocational Preference Inventory) (Holland, 1997), the SCII (Strong-Campbell Interest Inventory), and the SVIB (Strong Vocational Interest Blank) (Campbell \& Hansen, 1981), and the Vocational Preference Questionnaire Job-6 (Retowski, 2007), the last one being widespread in Poland, can be used to determine which vocational personality type dominates and what is the intensity of the characteristics of other types in the structure of the individual's vocational personality.

According to the assumptions of Holland's theory (1997), "Analogically to the six personality types, six types of job environments can be distinguished: realistic, investigative, artistic, social, enterprising, and conventional". In order to work effectively and to experience job satisfaction, a person should operate in an 
environment compatible with his/her vocational personality type (e.g., artistic personality-artistic work environments). Therefore, a career counselor working within Holland's framework should first asses the client's vocational personality type using one of available diagnostic tools, and then, together with the client, answer the question which occupations (thus, also work environments) correspond the client's personality. According to Holland (1997), relationships between the different vocational types (orientations) can be represented within a hexagon (see Figure 1).

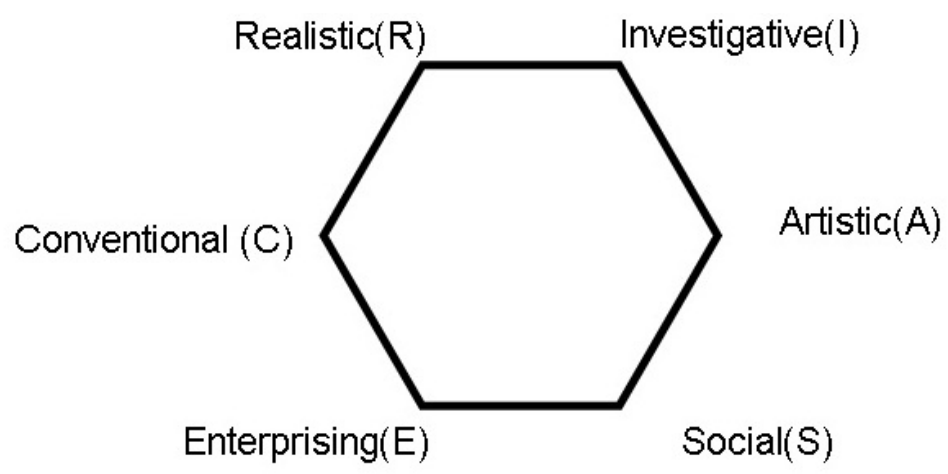

Figure 1. Six types of vocational personality. Source: Holland (1997).

The distances between the different vocational types presented in Figure 1 are not random. According to Holland (1997), they reflect the level of similarity between the types. The shorter the distance is between two vocational types within the hexagon, the closer the relationship is between them. For instance, the conventional type will have a relatively greater affinity to the realistic and enterprising types than to the artistic one.

Despite some major drawbacks (Paszkowska-Rogacz, 2003), factor-trait theories still enjoy a considerable popularity and have some practical advantages. Nevertheless, it should be remembered that questionnaire methods do not exhaust the wide range of options available to the modern career counselor. Many authors (e.g., Beail, 1985; Neimeyer, 1989a, 1989b, 1992; Peavy, 1992; Savickas, 1995; Spokane, 1992) emphasized that the Personal Construct Theory can be successfully applied to vocational guidance research and practice, as it represents a cognitive-developmental approach and responds to the demands of the postmodern era.

Therefore, the aim of this study is to present the application of the Personal Construct Theory (Kelly, 1955/1991) and the Rep Test as an alternative to Holland's scale.

According to Kelly, professional development is one of the fundamental aspects of a person's life, a factor that imparts to his/her life meaning and significance (Neimeyer, 1989a). In his theory, Kelly emphasized the existence of a separate system of vocational constructs (Vocational Construct System). This system comprises all constructs which are used by the individual to systematize the world of work and his/her career decision-making. It is used to plan, control, direct, and evaluate all of one's work-related behaviors and determines the paths followed by the individual while moving in the labor market (Savickas, 1997). The Vocational Construct System also provides a structured and dynamic Network of meanings, used by the individual to interpret occupational reality. Furthermore, it specifies the values that guide the individual when assessing the chances and opportunities encountered in his/her professional life. Thus, vocational interests can be understood as the result of interaction between a person's construct system and the social context in which he/she lives. A given professional role is consistent with the interests of a person only if it reflects the person's values and corresponds to his/her self-image (Savickas, 1997). While most people have similar dimensions in 
their Vocational Construct Systems (such as high salary-low salary, interesting work-monotonous work), it is absolutely certain that no two people have an identical systems of vocational constructs.

Neimeyer (1989a) stressed, therefore, that vocational guidance based on a constructivist approach, should be focused on the individual needs of each client and tailored for him/her. Spokane (1992) defined constructivist vocational guidance as a process in which the client's constructs are being discovered. Consequently, certain hypotheses regarding the possibilities of an alternative perception of the client's situation are formulated. In the next step, these hypotheses are tested in order to establish a new strategy. This process leads to the modification of an ineffective Vocational Construct System. Both the client and the counselor are active participants in the aforementioned process. A career counselor who works within a constructivist framework does not aim to find a fit between a client's characteristics and the labor market requirements, or to determine whether the client belongs to any particular group (as it is the case with questionnaire-based approaches). The task of the counselor is to focus the client's attention on the personal meaning that he/she attaches to the different elements of vocational reality. The objective is also to provide the clients with an opportunity to reflect on themselves and to experiment with alternative possibilities of constructing events. The counseling process should result in the development of the client's Vocational Construct System and the crystallization of the available career opportunities.

The Rep Test is a useful and relatively simple tool that can be successfully applied to vocational guidance. Neimeyer (1989a) listed some areas of research where the Vocational Rep Tests have been used as a central diagnostic method. These include testing structural models of professional development and studying career-related information processing as well as the hierarchy of career-related values. Beail (1985) also mentioned exploring students' perception of school subjects, selection of university degree programs, and perception of career counselors.

Based on the concepts presented above, the authors have formulated the following research questions:

(1) Do the subjective distances between professions belonging to the six work environments, represented on a perceptual map, reflect the objective relationships between them proposed in Holland's model?

(2) Do people with different vocational orientations (according to Holland's typology) represent different perceptual maps of professions?

(3) Do people with the same vocational orientations (according to Holland's typology) represent similar perceptual maps of professions?

\section{Method}

\section{Procedure and Sample}

The study consisted of two stages, both of which had an individual character. Data were gathered from a sample of students from the University of Lodz, the Technical University of Lodz, the Academy of Fine Arts in Lodz, and the Medical University of Lodz, who voluntarily participated in the study. During the first phase, the participants were asked to fill in the Vocational Preference Questionnaire Job-6 (Retowski, 2007). The questionnaire was administered via the Internet or in paper-and-pencil format, depending on the preferences of the participants. Confidentiality and anonymity were guaranteed. All the participants were offered feedback regarding the results of the study and their interpretation.

At the first stage, the study sample consisted of 136 students, 85 of whom were females and 51 males. The age of the participants varied from 19 to 27, with a mean of 21.97 and a standard deviation of 2.05 . 
The second phase of the study involved the administration of the Vocational Rep Test to a group of 60 students selected from the initial sample. The participants who took part in this stage of the study represented six different vocational orientations (each orientation being represented by a group of 10). The participants who were selected for this part of the study met all of the following criteria:

(1) They obtained high scores (stens 7-10) for one of the six vocational personality types, and low or average scores for the other ones or high scores (stens 7-10) for more than one personality type, but the difference between the scores for particular scales was at least two stens (e.g., score on the "artistic personality" scale $=$ sten 10; score on the "investigative personality" scale $=$ sten 7 -conclusion: the dominant personality type is "artistic", so the participant is to be assigned to the "artistic orientation" group);

(2) They agreed with the interpretation of their dominant vocational orientation presented to them after the end of the first stage of the study;

(3) They were willing to take part in the second phase of the study, which was more time-consuming.

The second stage of the study was preceded by a pilot's study on a group of volunteers, designed to develop the best method of implementing the Vocational Rep Test. Five-individual and two-group (two-member and four-member) Rep Tests were performed.

\section{Assessment and Measures}

Vocational orientation. Vocational orientation was measured at the first stage of the study using the Vocational Preference Questionnaire Job-6 by Retowski (2007). This method is based on Holland's Vocational Personality Typology (1997). The author of the scale pointed out that it can be used for screening tests that aim to gather basic information about the vocational orientation of the participants (Retowski, 2007). This was also the objective of this study when the authors decided to apply this method. The scale was composed of 29 items (e.g., "I am a person who knows how to give support to other people."). The participants were to respond using a 5 -point Likert scale $(5=$ Yes, $1=$ No). The results obtained by each participant were subsumed under six subscales, which corresponded to the six vocational orientations proposed by Holland (1997): realistic, investigative, artistic, social, enterprising, and conventional. The highest score was interpreted as a person's dominant vocational orientation.

The method had good psychometric values - Cronbach's alpha ranged from 0.67 for the enterprising orientation scale to 0.89 for the realistic orientation scale.

Vocational constructs. At the second stage of the study, the authors used a Vocational Rep Test to elicit the vocational constructs of the participants. In order to make comparisons between participants possible, the authors created a standardized model of the Rep Test, identical for all the participants. This study's Rep Test consisted of 12 elements - professions corresponding to the six vocational orientations (Holland, 1997), selected according to Podręcznik oceny zawodu (Profession Assessment Manual - a Polish handbook for Holland's typology, 1998) as follows:

(1) Artistic professions: journalist, musician;

(2) Investigative professions: university professor, microbiologist;

(3) Conventional professions: economist, programmer;

(4) Enterprising professions: lawyer, tour guide;

(5) Realistic professions: mechanical engineer, laboratory analyst;

(6) Social professions: psychologist and teacher. 
Since the participants in this study were students, all the selected professions required a university degree. Moreover, the authors aimed to choose those occupations which were well-known to the respondents, so that their names would leave no doubts as to their meaning, despite being general enough to allow a subjective interpretation.

The order of elements, the selection of triads, and the order in which they were presented were determined randomly and identical for all the Rep Tests conducted.

The participants generated constructs by themselves; however, the number of constructs was limited to six. The author decided to introduce this restriction in order to find a compromise between possible loss of some information, limiting the average test time (to 30 minutes), and adjusting the test to the abilities of the majority of the respondents. In the pilot study, the authors attempted to obtain a larger number of constructs, but in many cases, it turned out to be impossible. This also significantly prolonged the testing time and seemed to cause discomfort and frustration in those respondents who found it more difficult to create constructs.

The participants were asked to generate constructs and moreover, to assign them to a higher-level construct, "a job for me-not a job for me".

The respondents used a 5-point scale to rate the elements (professions). A rating of " 1 " corresponded to the "positive" and " 5 " to the "negative" pole of the construct.

\section{Results}

\section{Statistics}

MDS (Multi-dimensional Scaling) with MATLAB 2007b was used to analyze the data gathered from the Rep Tests. This technique was selected to consider the fact that its assumptions reflected the epistemological approach expressed in the Personal Construct Theory (Biela, 1992), and therefore, it seemed to be the most appropriate for this study.

MDS is an exploratory technique of data analysis which can be considered as an alternative to explanatory factor analysis. It aims to visualize the structure of data by displaying a pattern of proximities (similarities/dissimilarities or distances) as a low-dimensional geometrical space. MDS yields a set of $N$ points in a two- or three- dimensional space, arranged so that the Euclidean distances between them most accurately reflected (in terms of a selected criterion) the relationships between the elements from the input matrix.

The goodness of fit of this representation is gauged by a measure called STRESS (Standardized Residual Sum of Squares). The closer the STRESS value is to zero, the more exact the representation is. Zero indicates a perfect fit of a two- or three- dimensional model to the multidimensional reality, which is generally impossible to achieve in practice. The decision of what STRESS values correspond to a "good" or "poor" fit of the model to the input data is often discretionary and depends on the substantive value of the results of scaling. When using a normalized stress function (within the range of [0,1]), it is often assumed that values below 0.02 indicate a very good fit, between 0.02 and 0.05 - a good fit, between 0.05 and $0.1-$ a moderate fit, and over 0.1 - a poor fit (Kruskal, 1978, quoted in Zaborski, 2001).

Input data for MDS must be in the form of a symmetric, one-mode matrix of relationships between a set of items (Van Deun \& Delbeke, 2000).

Nonmetric MDS was used due to the fact that the data on similarities were qualitative (rank-ordered, measured on an ordinal 5-point scale). The objective was to reconstruct the perceptual maps of 12 professions generated by the participants. To do so, the authors had to visualize the relationships (distances) between the 
professions within this space on a plane, producing a two-dimensional picture. Euclidean distance was used to model relationships between the objects.

\section{Data Analysis}

As mentioned above, the objective of this study was to reconstruct part of the multidimensional psychological space of the respondents, namely, the cognitive representation of relationships between 12 professions representing six vocational orientations. In the following section, the authors will present the results obtained by mapping them on a two-dimensional space.

First, the authors analyzed distances between the 12 professions in a two-dimensional space for the six groups of participants taken together $(N=60)$. A graphical representation of the results is given in Figure 2 .

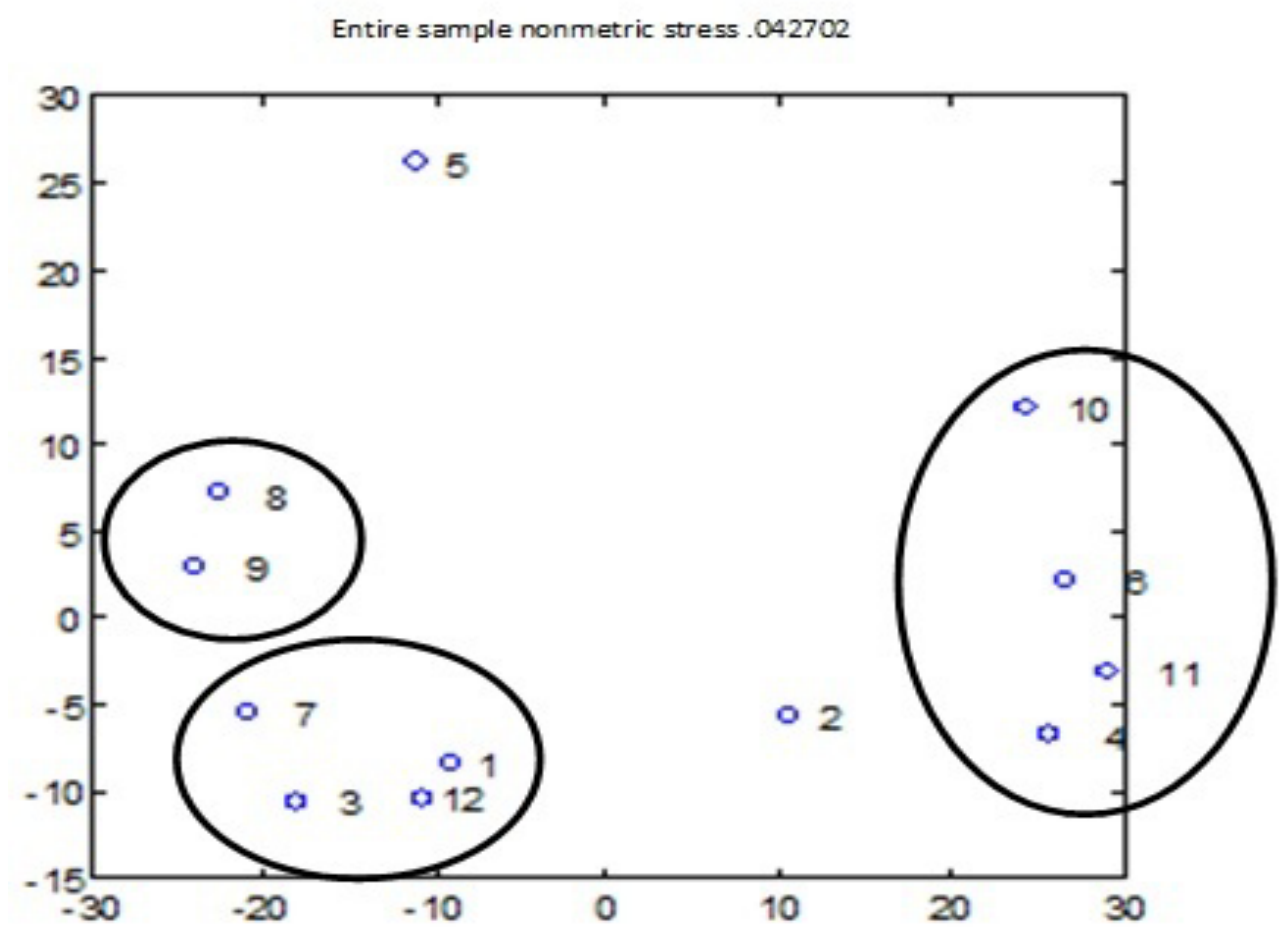

Figure 2. Graphical representation of distances between 12 professions in a two-dimensional space. Notes. Results for the entire sample $(N=60)$; 1: university professor; 2: economist; 3: lawyer; 4: microbiologist; 5: musician; 6: mechanical engineer; 7: psychologist; 8: journalist; 9: tour guide; 10: programmer; 11: laboratory analyst; 12: teacher.

Considering the results presented above, the authors concluded that:

(1) In the perceptual space of the participants (see Figure 2), the 12 presented professions form different clusters are from those proposed in the Profession Assessment Manual (1998) based on Holland's theory (1997). General trends indicating the similarity of certain occupations are to some extent confirmed. However, the respondents seem to see the professional world differently from Holland's assumptions. Sufficing it to note that only two occupations belong to the same vocational orientation actually form the same cluster (mechanical engineer and laboratory analyst). The other clusters are composed of professions classified by Holland as belonging to different, usually adjacent, types of vocational orientation;

(2) The distances between different professions postulated by Holland (1997) are not exactly reflected in the analyzed sample. However, they are also not completely ignored. It seems that the respondents, probably 
intuitively, took them into account, but used other criteria to classify the professions as similar or different from each other. It can be observed, for instance, that not only "enterprising" and "social" professions (Holland's 2nd degree of convergence), but also "social" and "investigative" professions (Holland's 3rd degree of convergence), and even "enterprising" and "investigative" professions (Holland's 4th degree of convergence) are relatively close to each other on the reconstructed perceptual map (see Figure 2).
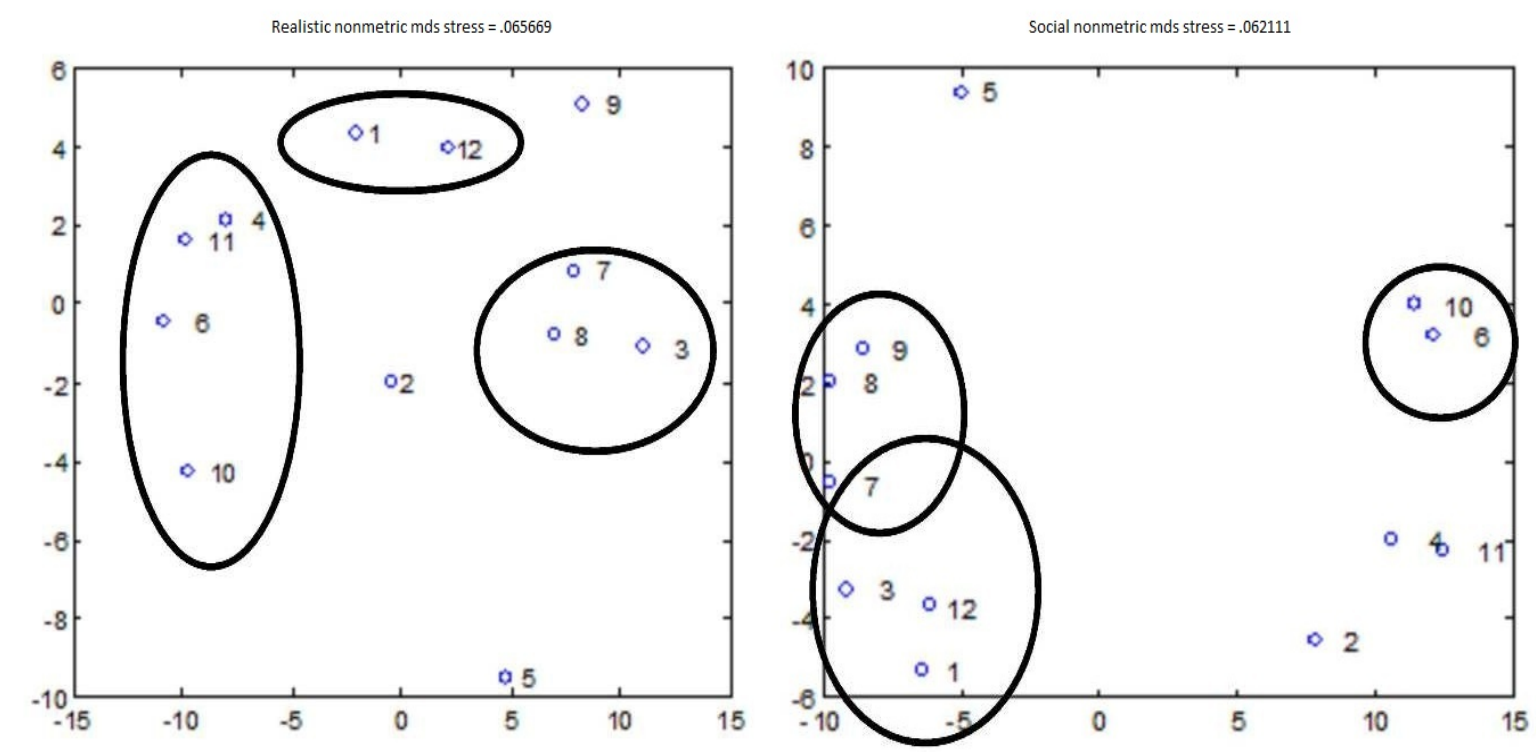

Figure 3. Graphical representation of distances between 12 professions in a two-dimensional space. Notes. Results for the respondents with realistic $(N=10)$ and social $(N=10)$ vocational orientation; 1: university professor; 2: economist; 3: lawyer; 4: microbiologist; 5: musician; 6: mechanical engineer; 7: psychologist; 8: journalist; 9: tour guide; 10: programmer; 11: laboratory analyst; 12 : teacher.
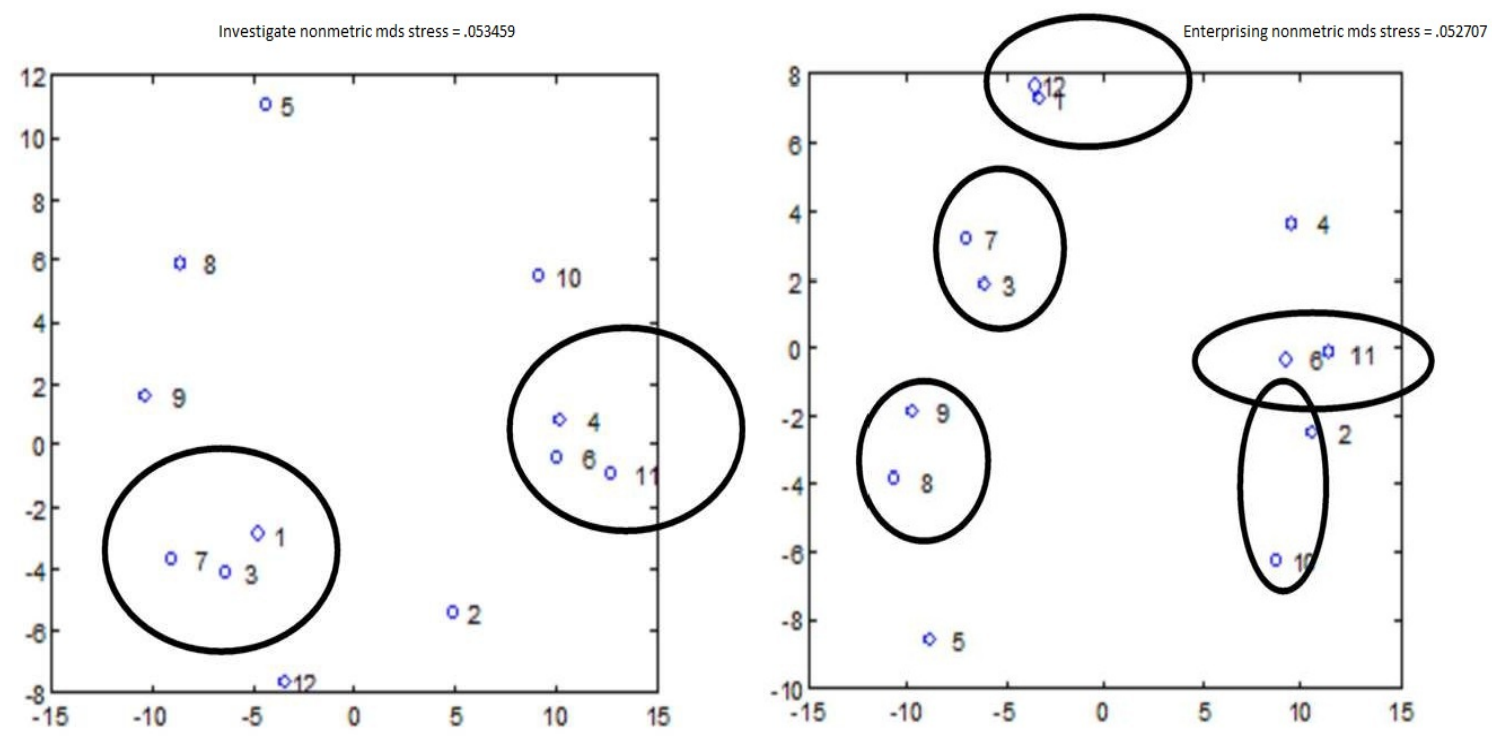

Figure 4. Graphical representation of distances between 12 professions in a two-dimensional space. Notes. Results for the respondents with investigative $(N=10)$ and enterprising $(N=10)$ vocational orientation; 1 : university professor; 2 : economist; 3: lawyer; 4: microbiologist; 5: musician; 6: mechanical engineer; 7: psychologist; 8: journalist; 9: tour guide; 10: programmer; 11: laboratory analyst; 12: teacher. 
Subsequently, the authors made a pairwise comparison between the perceptual maps of respondents who represented vocational orientations located diagonally on Holland's hexagon (the lowest level of convergence of elements within the personality model). Figures 3-5 present the results of comparison between groups with the following vocational orientations: social vs. realistic; investigative $v s$. enterprising, and artistic $v s$. conventional. The relationships between the 12 professions are shown in a two-dimensional space.

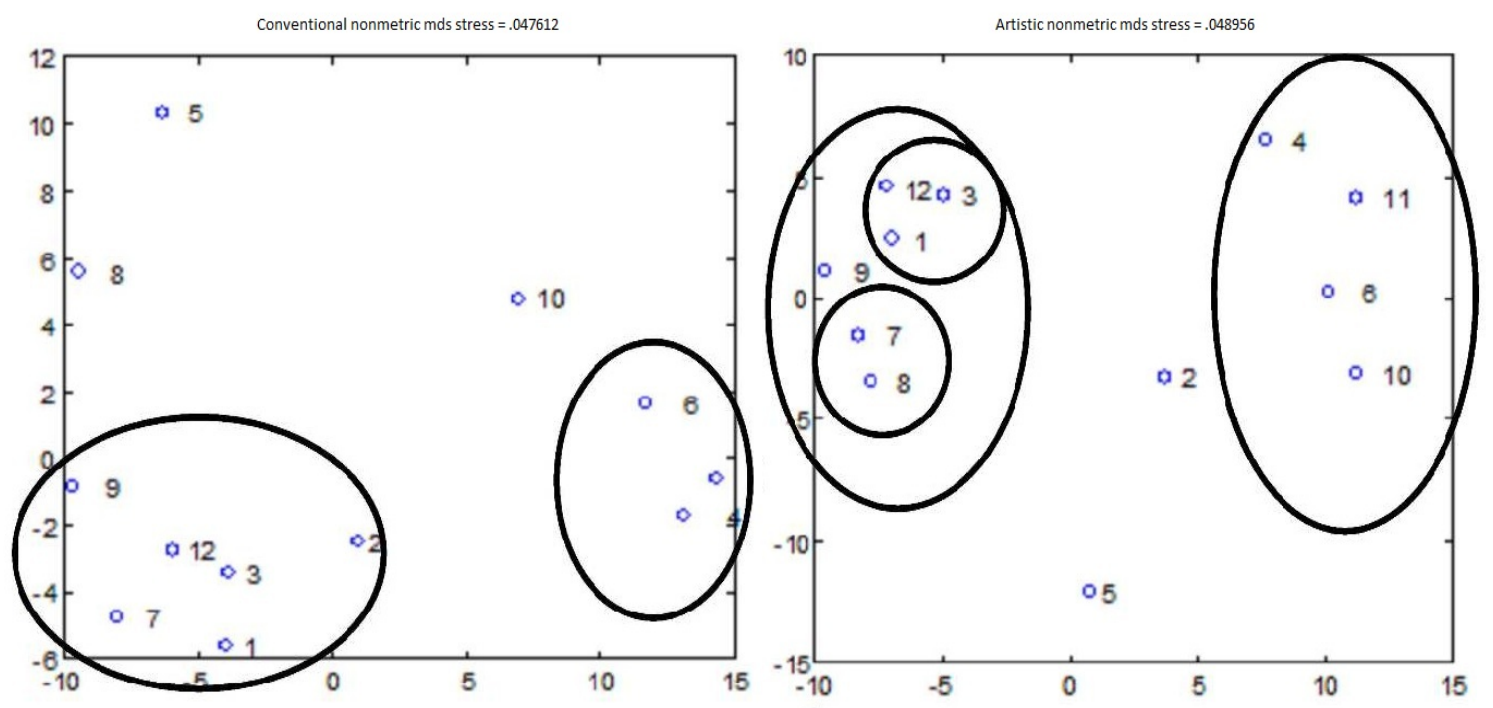

Figure 5. Graphical representation of distances between 12 professions in a two-dimensional space. Notes. Results for the respondents with conventional $(N=10)$ and artistic $(N=10)$ vocational orientation; 1 : university professor; 2 : economist; 3: lawyer; 4: microbiologist; 5: musician; 6: mechanical engineer; 7: psychologist; 8: journalist; 9: tour guide; 10: programmer; 11: laboratory analyst; 12 : teacher.

Based on the results presented above, the authors made the following conclusions:

(1) Maps of distances between professions are not identical. Therefore, one can assume that the perception of different occupations varies, depending on the type of vocational personality of the respondent group;

(2) Nevertheless, some common tendencies, also reflected in the perceptual map of the entire sample (see Figure 2), are maintained. These are as follows:

- Two professions: Musician (artistic orientation) and economist (conventional orientation) are isolated. This result indicates that they are perceived as distinct from other occupations: They are unlike each other and unlike any of the other listed professions;

- The remaining 10 professions are divided, in the perception of the respondents, into two clearly distinct groups: (a) A group tentatively called "humanistic" includes the following professions: university professor, lawyer, journalist, tour guide, and teacher; (b) A group tentatively called "scientific" includes the following professions: microbiologist, mechanical engineer, programmer, and laboratory analyst.

The final stage of data analysis consisted of a comparison of distances between the 12 professions in a two-dimensional space for two individuals with the same vocational orientation. The authors compared the distance matrixes of two randomly selected participants with the artistic vocational orientation (the choice of the orientation itself was also random). The results of this comparison can be seen in Figure 6.

The conclusions that the authors made on the basis of a comparison of the results of two respondents— Joanna and Gosia—are as follows: 
(1) Although both respondents have the same vocational orientation (artistic), their perceptual maps of the 12 professions differ from each other. Therefore, one can conclude that Gosia and Joanna perceive relationships between the occupations differently;

(2) The general tendency to split the professions into two clusters, demonstrated in the previous results, is preserved in both cases.
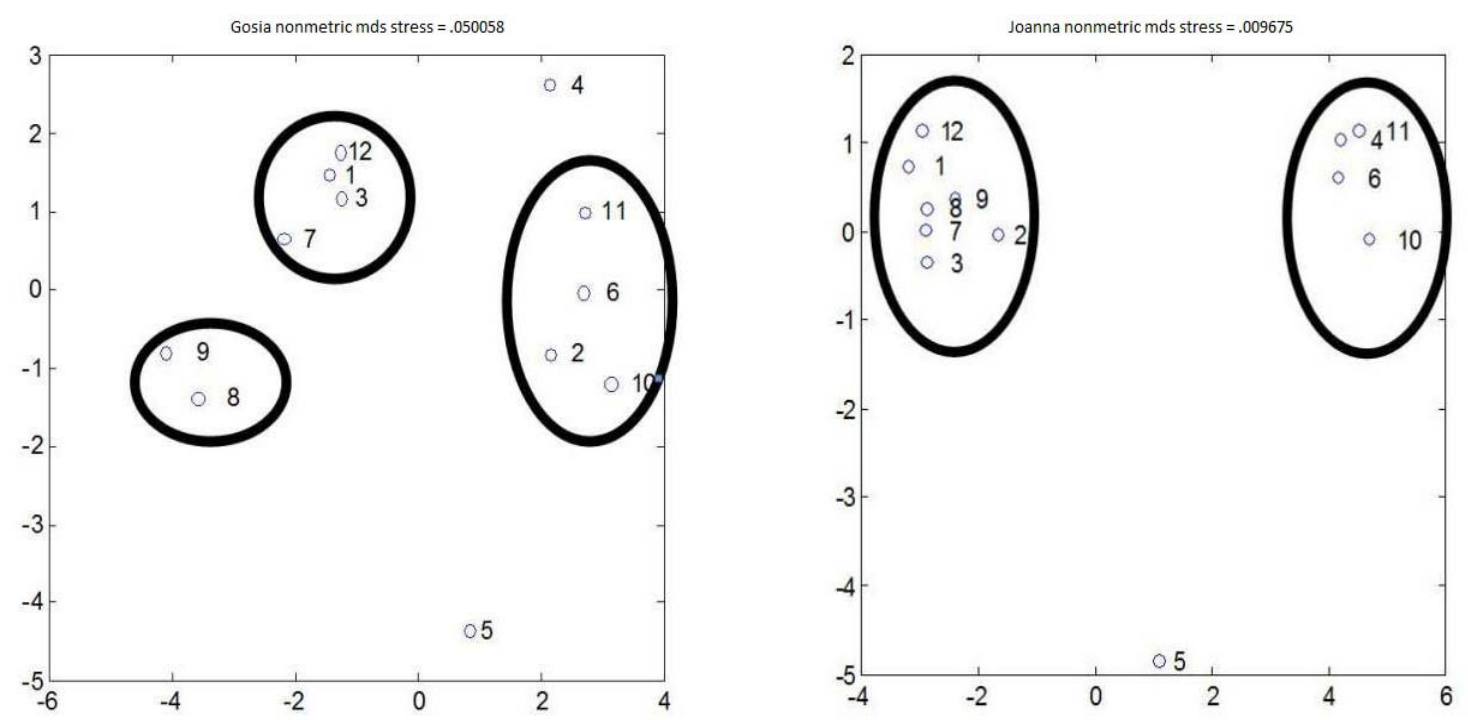

Figure 6. Graphical representation of distances between 12 professions in a two-dimensional space. Notes. Comparison of results for two respondents with artistic vocational orientation; 1: university professor; 2: economist; 3 : lawyer; 4: microbiologist; 5: musician; 6: mechanical engineer; 7: psychologist; 8: journalist; 9: tour guide; 10: programmer; 11: laboratory analyst; 12 : teacher.

\section{Discussion}

The aim of the present study was neither to undermine the assumptions of Holland's theory (1997), nor to criticize it. Holland's Vocational Personality Typology is an approach which has a well-established position in the field of vocational guidance. Many studies have confirmed its substantive value and practical applicability. However, its assumptions about human nature and career development are, in many instances, opposite to those proposed by Kelly (1955/1991). Therefore, it was compared with the Personal Construct Theory.

Based on the results of the present study, the following conclusions can be made:

Firstly, the distances between the 12 analyzed professions, observed in the reconstructed perceptual space of the participants, do not reflect the relationships postulated in Holland's hexagonal model (1997). Moreover, this discrepancy varies depending on the type of vocational orientation represented by the different professions. "Realistic" profession is perceived most consistently, while "artistic" ones vary most;

Secondly, people with different vocational personality types (within Holland's typology) also differ in terms of the location of different professions on their perceptual maps. One's vocational personality type may be, therefore, regarded as an important factor, which influences the way in which one perceives elements of the labor market.

While the evaluation of different professions (on a scale "a job for me-not a job for me") differs significantly depending on the type of vocational personality of the evaluators, there is no simple relationship 
between the rating of a profession and the degree of similarity between the evaluator's vocational orientation and the vocational orientation represented by the evaluated profession. Thus, vocational personality type cannot be regarded as the only factor that affects a person's career preferences.

The above presented findings indicate that the data gathered on the basis of the personal constructs generated by the respondents are not identical with the data provided by analysis of the Vocational Preference Questionnaire based on Holland's model (1997). This fact supports the hypothesis that factor-trait theories do not fully explain all psychological processes, including those related to career decision-making and effective performance in the labor market. In particular, it is unrealistic to expect that these processes will be explained on the basis of the results of only one questionnaire, even the best one. This opinion was corroborated by Prediger (Bajcar, Borkowska, Czerw, Gąsiorowska, \& Nosal, 2006), who critically assessed the practical value of Holland's theory, and decided to analyze and develop it. As a result of his studies, he proposed the "World-of-Work Map", in which he modified and enriched the classification of professions proposed by Holland.

The Personal Construct Theory seems to be a valid approach, complementary to the factor-trait theoretical framework. It affords a different perspective on the client's personality, takes the role of developmental and cognitive processes into account, and offers a tool for obtaining both quantitative and qualitative data. Effective career counseling might be based on an integration of the constructivist approach with the use of questionnaire-based methods, which allow a fast, general diagnosis of one's vocational personality.

The results indicate many interesting lines of future research regarding the Personal Construct Theory and the Rep Test. These may include areas, such as analysis of the social perception of different occupations (e.g., psychologist, career counselor), analysis of the personal constructs of different professional groups, and analysis of the relationship between the characteristics of the client and the Rep Test suitable for him/her.

On the basis of the obtained results, it can be concluded that the Rep Test based on Kelly's (1955/1991) Personal Construct Theory is a useful diagnostic tool, whose application should be considered in counseling practice. When properly performed, it is a valuable source of information about the client. Not only does it allow one to gain knowledge about the client's individual system of meanings, but also to assess the level of his/her cognitive development and to reconstruct part of his/her perceptual space.

Thanks to its flexibility, this approach is adaptable to the objectives of various types of study and adjustable to the specific needs of the client.

Based on analysis of the Rep Test, the counselor is able to predict how the client will perform on the labor market, what is likely to cause difficulties for him/her and what criteria he/she will use in making career-related decisions. These conclusions confirm previous findings in career counseling research (Neimeyer, 1989a, 1989b; Savickas, 1997).

Notwithstanding its many advantages, the Rep Test is a diagnostic tool that also has some limitations. First, its application (including administration, interpretation, and discussion with the client) takes a relatively long time. Some counselors may not have a sufficient amount of time during one session, while a hurried administration would significantly affect the quality of obtained results.

Moreover, both the administration and the interpretation of the Rep Test require the counselor of some practice and a thorough understanding of the Personal Construct Theory. It is by no means a difficult technique, but it cannot be compared with questionnaire methods in terms of simplicity of administration. As any qualitative technique, the Rep Test also requires adequate conditions, in which the client would feel 
comfortable and safe.

Another limitation observed during the present study is that the Rep Test technique requires high levels of motivation, attention, and activity of the client. Only under such conditions will the obtained results be valid. This factor indicates that the Rep Test does not seem to be the best method when working with clients who demonstrate resistance, are not motivated, or are in poor mental or physical shape.

Finally, according to what the authors observed during this study, the Rep Test is the most useful with those clients who demonstrate greater openness to experience, greater capacity of abstract thinking, and higher verbal skills. First, the administration of the test is faster and more efficient; Second, the quality of the obtained results is higher (for instance, more functionally non-identical constructs); and Finally, these clients seem to be more confident with the method, have a better opinion of it, demonstrate a higher level of motivation, and experience more positive emotions during the testing process. However, it is worth noting that the psychological characteristics of the respondents were assessed only by observing their behavior; no personality or intelligence tests were applied. Research conducted by other scholars did not confirm any significant relationships between the client's intellectual capacity and his/her ability to take a Rep Test (Beail, 1985). Verification of this application-related aspect of the approach is thus a potential direction for future research.

\section{References}

Bajcar, B., Borkowska, A., Czerw, A., Gąsiorowska, A., \& Nosal, C. (2006). Psychology of vocational preferences and interests: Review of theory and methods (Psychologia preferencji i zainteresowań zawodowych. Przegląd teorii i metod). Warsaw: Ministry of Labor and Social Policy.

Beail, N. (1985). Using repertory grid technique with severely physically disabled people. In N. Beail (Ed.), Repertory grid technique and personal constructs: Application in clinical and educational settings. London: Croom Helm.

Biela, A. (1992). Multidimensional scaling as a research method (Skalowanie wielowymiarowe jako metoda badań naukowych). Lublin: Towarzystwo Naukowe KUL.

Boeree, G. (2006). George Kelly (Electronic textbook). Shippensburg University Psychology Department. Retrieved from http://webspace.ship.edu/cgboer/kelly.html

Campell, D. P., \& Hansen, J. C. (1981). Manual for the SVIB-SCII. Stanford, C. A.: Stanford University Press.

Côté, J. E. (1996). Co identity: A multidimensional analysis. In G. R. Adams, R. Montemayor, \& T. P. Thomas (Eds.), Psychosocial development during adolescence (pp. 130-180). Thousand Oaks, US, C. A.: Sage Publications.

Czapiński, J. (1978). Rep Test methodology-Theoretical basis, examples of tools, evaluation of psychometric values (Metodologia RepTestu—podstawy teoretyczne, przykłady technik, ocena wartości pomiarowych). In L. Wołoszynowa (Ed.), Materials for teaching psychology (Materiały do nauczania psychologii, Vol. 3, S. III, pp. 277-306). Warsaw: PWN.

Fransella, F., \& Dalton, P. (2000). Personal construct counselling in action. London: SAGE.

Holland, J. L. (1997). Making vocational choices. Odessa, Florida: Psychological Assessment Resources, Inc..

Holland, J. L., Powell, A. B., \& Fritzche, B. A. (1994). The self-directed search professional user's guide. Odessa, F. 1.: Psychological Assessment Recourses.

Jankowicz, D. (2004). The easy guide to repertory grids. West Sussex: Wiley.

Kelly, G. A. (1955/1991). The psychology of personal constructs. New York: Norton (Reprinted by Routledge, London, 1991).

Kelly, G. A. (1966). A brief introduction to Personal Construct Theory. In F. Fransella (Ed.), International handbook of personal construct psychology. West Sussex: John Wiley \& Sons Ltd..

Kofta, J., \& Doliński, D. (2004). A cognitive approach to personality (Poznawcze podejście do osobowości). In J. Strelau (Ed.), Psychology: An academic handbook (Psychologia Podręcznik akademicki, Vol. 2, pp. 561-600). Gdańsk: GWP.

Neimeyer, G. J. (1989a). Applications of repertory grid technique to vocational assessment. Journal of Counselling and Development, 67, 585-589. 
Neimeyer, G. J. (1989b). Personal construct systems in vocational development and information processing. Journal of Career Development, 16, 83-96.

Neimeyer, G. J. (1992). Personal constructs in career counseling and development. Journal of Career Development, 236, 163-173.

Paszkowska-Rogacz, A. (2003). Psychological foundations of career choice: An overview of theoretical frameworks (Psychologiczne Podstawy Wyboru Zawodu. Przegląd Koncepcji Teoretycznych). Warsaw: Krajowy Ośrodek Wspierania Edukacji Zawodowej i Ustawicznej.

Pervin, L., \& John, O. (2002). Personality: Theory and research (Osobowość-teoria i badania). Cracow: Wydawnictwo Uniwersytetu Jagiellońskiego.

Peavy, V. (1992). Constructivism, existential themes and counselling. Paper presented at the conference Intercultural Counsellig and Therapy. Vancouver.

Profession Assessment Manual (Podręcznik oceny zawodu). (1998). Zeszyty informacyjno-metodyczne doradcy zawodowego (p. 8). Warsaw: Krajowy Urząd Pracy.

Retowski, S. (2007). Vocational preference questionnaire job-6 (Opracowanie Kwestionariusza Preferencji Zawodowych Job-6). Retrieved October 20, 2009, from http://www.doradca-zawodowy.pl/index.php?option=com_content\&task=view\&id=85\& Itemid $=40$

Savickas, M. (1995). Constructivist counselling for career indecision. The Career Development Quarterly, 43, 363-373.

Savickas, M. (1997). Constructivist career counselling: Models and methods. Advances in Personal Construct Psychology, 4, 149-182.

Smith, M., Hartley, J., \& Stewart, B. (1978). A case study of repertory grids used in vocational guidance. Journal of Occupational Psychology, 51, 97-104.

Spokane, A. (1992). Personal constructs and careers: A reaction. Journal of Career Development, 18, 229-235.

Van Deun, K., \& Delbeke, L. (2000). Multidimensional scaling. Leuven: University of Leuven. Retrieved from http://www.mathpsyc.uni-bonn.de/doc/delbeke/delbeke.htm

Zaborski, A. (2001). Multidimensional scaling in market research (Skalowanie Wielowymiarowe w Badaniach Marketingowych). Wrocław: Akademia Ekonomiczna. 